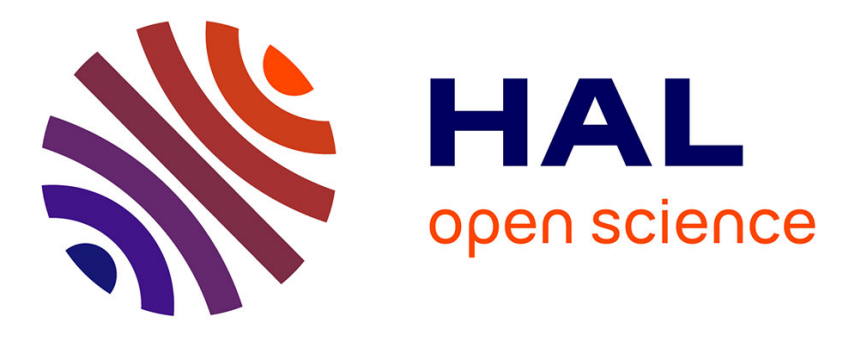

\title{
Photoluminescence from Si/Si0.87Ge0.13 multiple quantum well wires
}

Y. Tang, C. Sotomayor Torres, C. Wilkinson, D.W. Smith, T. Whall, E. Parker

\section{- To cite this version:}

Y. Tang, C. Sotomayor Torres, C. Wilkinson, D.W. Smith, T. Whall, et al.. Photoluminescence from $\mathrm{Si} / \mathrm{Si} 0.87 \mathrm{Ge} 0.13$ multiple quantum well wires. Journal de Physique IV Proceedings, 1993, 03 (C5), pp.C5-119-C5-122. 10.1051/jp4:1993521 . jpa-00251607

\section{HAL Id: jpa-00251607 https://hal.science/jpa-00251607}

Submitted on 1 Jan 1993

HAL is a multi-disciplinary open access archive for the deposit and dissemination of scientific research documents, whether they are published or not. The documents may come from teaching and research institutions in France or abroad, or from public or private research centers.
L'archive ouverte pluridisciplinaire HAL, est destinée au dépôt et à la diffusion de documents scientifiques de niveau recherche, publiés ou non, émanant des établissements d'enseignement et de recherche français ou étrangers, des laboratoires publics ou privés. 


\title{
Photoluminescence from $\mathrm{Si} / \mathrm{Si}_{0.87} \mathrm{Ge}_{0.13}$ multiple quantum well wires
}

\author{
Y.S. TANG, C.M. SOTOMAYOR TORRES, C.D.W. WILKINSON, D.W. SMITH*, T.E. WHALL* \\ and E.H.C. PARKER*
}

Nanoelectronics Research Centre, Department of Electronics and Electrical Engineering, University of Glasgow, Glasgow G12 8QQ, U.K.

* Department of Physics, University of Warwick, Coventry CV4 7AL, U.K.

\begin{abstract}
This paper reports a low temperature photoluminescence study of the optical properties of a series of dry etched free standing strained layer $\mathrm{Si} / \mathrm{Si}_{0.87} \mathrm{Ge}_{0.13}$ multiple quantum well wires with lateral dimensions between $40 \mathrm{~nm}$ and $500 \mathrm{~nm}$. The results show that dry etching induces partial strain relaxation. An enhanced electron-hole droplets emission from the Si layers with reducing wire width was observed due to both the extra surface roughness introduced during the etching process, which accelerates the nucleation of the droplets formation, and the effect of lateral confinement. A new feature at $1.131 \mathrm{eV}$ at $4 \mathrm{~K}$ related to unknown impurity states located at the heterointerfaces was also detected.
\end{abstract}

The optical properties of semiconductor nanostructures, such as quantum wires and dots fabricated by using different techniques, have been of world-wide interest ${ }^{[1]}$ recently due to their potential applications in device engineering. $\mathrm{Si} / \mathrm{Si}_{1-\mathrm{x}} \mathrm{Ge}_{\mathrm{x}}$ heterostructures, as one of the recently emerged new materials, have also been widely investigated[2-5] with most of the emphasis on optical properties of quasi-two dimensional (2D) structures. With the application of electron beam lithography and reactive ion etching, nanostructures have been successfully fabricated in modulation doped $\mathrm{p}^{+-S i} / \mathrm{Si}_{1-\mathrm{x}} \mathrm{Ge}_{\mathbf{x}}$ heterojunctions with feature size down to $15 \mathrm{~nm} .[6,7]$ Due to the extremely low sidewall damage inflicted during dry etching of $\mathrm{Si} / \mathrm{Si}_{1-\mathrm{x}} \mathrm{Ge}_{\mathrm{x}}$ system as compared to $\mathrm{GaAs} / \mathrm{Al}_{1}$. ${ }_{x} \mathrm{Ga}_{x}$ As system, ${ }^{[8]}$ the study of the the physical properties of $\mathrm{Si} / \mathrm{Si}_{1-\mathrm{x}} \mathrm{Ge}_{\mathrm{x}}$ nanostructures is most promising. Our previous studies on the optical properties of nanostructured wires based on a modulation doped $\mathrm{p}^{+}-\mathrm{Si} / \mathrm{SiGe} 2 \mathrm{D}$ hole gas indicate that a strain relaxation process occurs during the wire fabrication and a blue shift of quantum confined transitions with reducing lateral dimension down to below about $40 \mathrm{~nm}$ can be observed.[6,7] In this paper, we report a study on the photoluminescence (PL) of a series of $\mathrm{Si} / \mathrm{Si}_{1-\mathrm{x}} \mathrm{Ge}_{\mathrm{x}}$ multiple quantum well $(\mathrm{MQW})$ wires. In addition to the features similar to 
those reported on the 2D hole gas wires, an enhanced electron-hole droplet (EHD) emission and a new feature related to impurity states at the $\mathrm{Si} / \mathrm{Si}_{1-\mathrm{x}} \mathrm{Ge}_{\mathrm{x}}$ heterointerfaces have been observed in the MQW wires.

The original material was grown by molecular beam epitaxy (MBE) on a (100) oriented $\mathrm{n}^{-}-\mathrm{Si}\left(\mathrm{e}^{2} 20 \Omega-\mathrm{cm}\right)$ substrate. The MBE sample has 30 periods of $\mathrm{Si} / \mathrm{Si}_{0.87} \mathrm{Ge}_{0.13}$ MQWs with the well and barrier widths of $8 \mathrm{~nm}$ and $21 \mathrm{~nm}$, respectively, grown on a $200 \mathrm{~nm} \mathrm{Si}$ buffer layer. They were first scribed into a series of $5 \mathrm{~mm} \times 5 \mathrm{~mm}$ chips, and then cleaned and patterned with wires of different sizes by using electron beam lithography and lift-off of the resist.

The reactive ion etching was performed on a planar reaction chamber system operated at an $\mathrm{rf}$ frequency of $13.56 \mathrm{MHz}$. The etching gas was $99.99 \%$ pure $\mathrm{SiCl}_{4}$. By using optimized etching parameters, i.e. an if power of $35 \mathrm{~W}$, a gas flow rate of $2.25 \mathrm{sccm}$, and a chamber pressure of $10.8 \mathrm{~m}$ Torr, which gives an etching rate of $25 \mathrm{~nm} / \mathrm{min}$, we obtained a series of $2.5 \mu \mathrm{m}$ long wires with their widths between $40 \mathrm{~nm}$ and $500 \mathrm{~nm}$ and pitch size of $750 \mathrm{~nm}$. The etched depth was kept to about $0.6 \mu \mathrm{m}$, i.e. half of the MQW layers was cut into wires, so that signals from both the wires and the remaining MQWs could be observed simultaneously, and the latter serves as a control sample in the experiments.

The PL spectra were measured at temperatures between $4 \mathrm{~K}$ and $20 \mathrm{~K}$ on a standard cryostat system, using the $488 \mathrm{~nm}$ line of an $\mathrm{Ar}^{+}$ion laser with a power density variable between 0.1 and $50 \mathrm{~W} / \mathrm{cm}^{2}$. The PL signal was detected by a liquid $\mathrm{N}_{2}$ cooled Ge detector through a Jobin-Yvon THR1000 monochromator.

Fig.1 shows the PL spectra of a MQW sample (curve b) and four wire samples (curves c-f) at $4 \mathrm{~K}$. For comparison, a PL spectrum from a deep etched sample (curve a) is also plotted in Fig.1, from which all the epitaxially grown layers were removed. The PL spectra were obtained by illuminating a constant area on samples with different lateral sizes, i.e. less MQW areas were exposed to the laser beam during the measurements with reducing wire width. It can be seen that peaks 1 and 4 are from the substrate, which are the bound exciton no-phonon line $\left(\mathrm{BE}_{\mathrm{Si}}\right)$ and the TO phonon assisted bound exciton $\left(\mathrm{BE}^{\mathrm{TO}} \mathrm{Si}\right)$ line, ${ }^{[2,3]}$ respectively; peaks 3 and 5 are TO phonon assisted free exciton $\left(\mathrm{FETO}_{\mathrm{Si}}\right)$ line and the $\mathrm{EHD}$ emission is related to the $\mathrm{Si}$ buffer layer or the $\mathrm{Si}$ layers in the MQWs, which is about $12 \mathrm{meV}$ below the $\mathrm{BETO}_{\mathrm{Si}}$ line. It is clear that even with less illuminated areas on the wires, an enhanced luminescence of EHD with reducing wire width is observed under the same excitation condition. This is possibly due to the wire confinement and/or the increasing surface roughness $[9,10]$ introduced during the wire fabrication process, which improves the formation of the nucleation of the droplets, leading to stronger PL in the experiments. In addition to the peaks discussed above, other excitonic features (peaks 6-8) related to the SiGe layers in the MQWs are also observed, which are no-phonon and TO phonon assisted PL lines. The low energy broad band transition (band 9) at $\sim 0.8 \mathrm{eV}$ existing in both the MQWs and a $500 \mathrm{~nm}$ wide wire sample might be related to strain or dislocations, and a new feature $X_{I}$ (peak 2) located between the no-phonon and TO phonon assisted Si PL lines emerges in both the MQWs and the wire samples. Peak 2 is from the Si buffer layer or the Si layers in the MQWs due to its energy position. When the wire width is reduced to about $200 \mathrm{~nm}$, the broad band 9 disappears, a new defect-related peak (peak 10) emerges at $0.76 \mathrm{eV}$ and the peaks related to the SiGe layers (peaks 6,7 ) split into two. The splitting suggests that strain relaxation occurred during dry etching. While the splitting of peak 2 suggests that it comes from the Si layers in the MQWs due to that only half of the MQWs was etched 
away, no double structure should be seen if it were from the Si buffer layer. The blue shift of the split peak is due to strain relaxation in the Si layers as half of the MQWs was etched away.

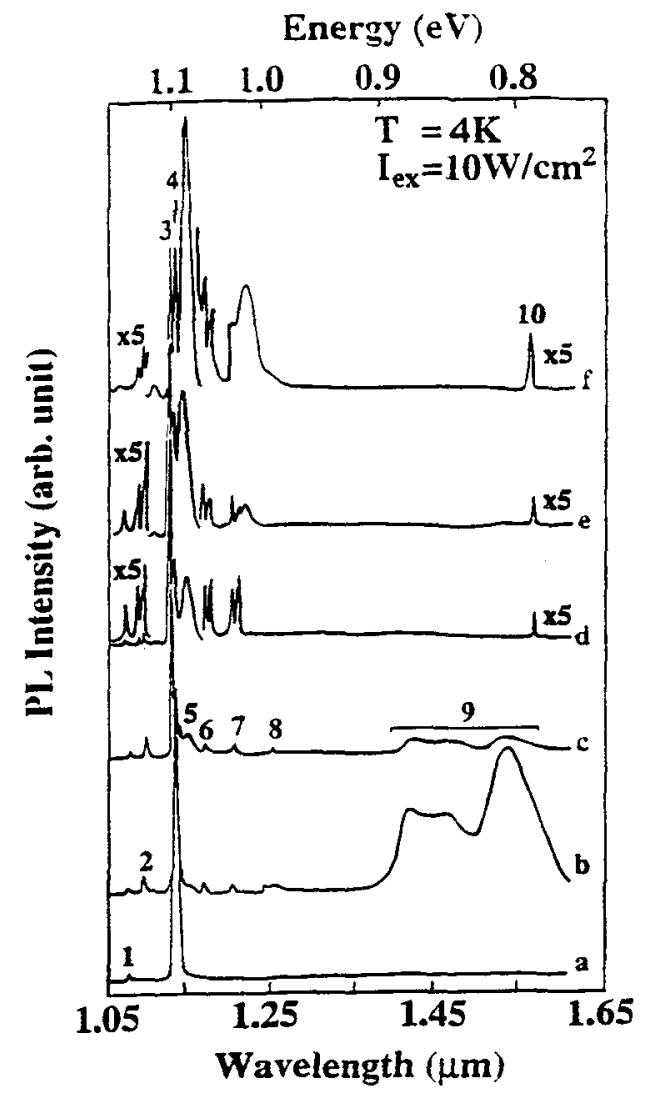

Fig.1 PL spectra of different samples at $4 \mathrm{~K}$. The excitation power was $10 \mathrm{~W} / \mathrm{cm}^{2}$. The peaks are marked by numbers: (1): $\mathrm{BE}_{\mathrm{Si}} ;$ (2): $\mathrm{X}_{\mathrm{I}}$; (3): FETO $_{\mathrm{Si}} ;$ (4): $\mathrm{BETO}_{\mathrm{Si}}$; (5): EHD; (6): $\mathrm{X}^{\mathrm{NP}} \mathrm{Si}-\mathrm{Ge}$; (7): SiGe related; $(8): \mathrm{X}^{\mathrm{TO}}{ }_{\mathrm{Si}-\mathrm{Ge}} ;(9)$ : strain related; (10): defects.
(a) deep etched sample;
(b) multiple quantum wells;
(c) $2.5 \mu \mathrm{m} \times 500 \mathrm{~nm}$ wires;
(d) $2.5 \mu \mathrm{m} \times 200 \mathrm{~nm}$ wires;
(e) $2.5 \mu \mathrm{m} \times 100 \mathrm{~nm}$ wires;
(f) $2.5 \mu \mathrm{m} \times 40 \mathrm{~nm}$ wires.

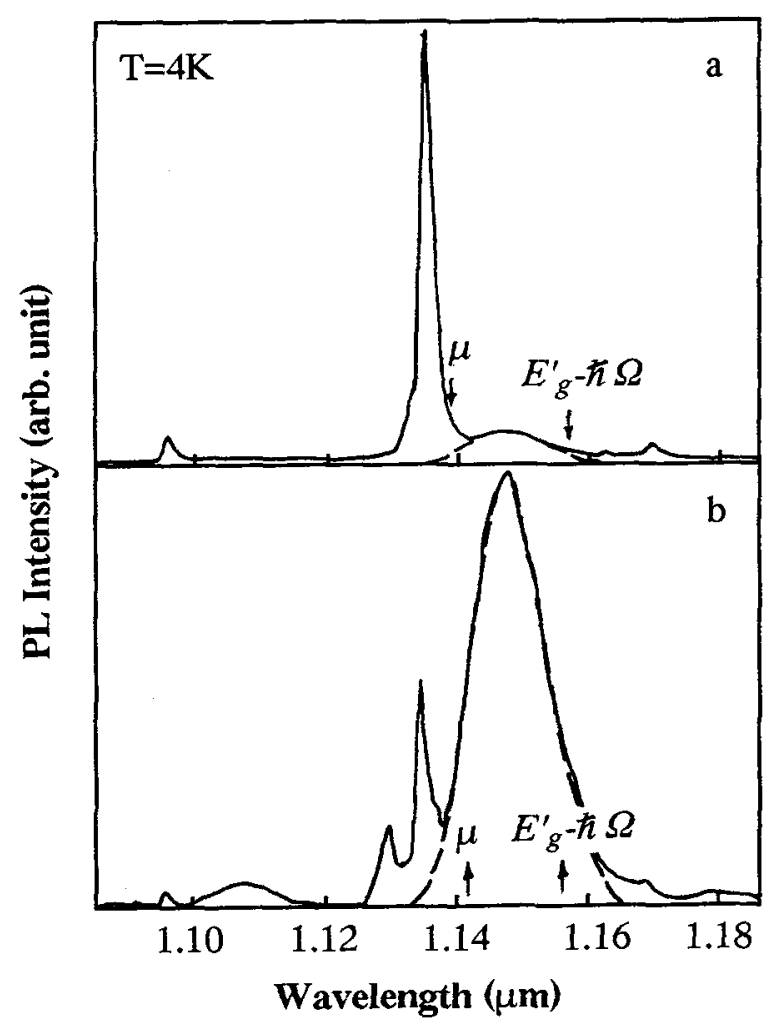

Fig.2 Line shape fitting of the EHD emission from two samples. The solid lines are experimental PL spectra at $4 \mathrm{~K}$, and the dashed lines are least square fittings to the EHD emissions. The arrows marked the positions of $\mu$ and $\mathrm{E}_{\mathrm{g}}^{\prime}-\hbar \Omega$, where $\hbar \Omega$ is the TO phonon energy. (a) $2.5 \mu \mathrm{m} \mathrm{x}$ $500 \mathrm{~nm}$ wires; (b) $2.5 \mu \mathrm{m} \times 40 \mathrm{~nm}$ wires.

Fig. 2 show an example of line shape analysis on the EHD emission observed in Fig.1. Spectrum $a$ is from the $500 \mathrm{~nm}$ wires and spectrum $b$ from the $40 \mathrm{~nm}$ wires. Parameters such as $E_{g}^{\prime}$, the renormalized band gap energy, the chemical potential $\mu$, and 
the electron-hole pair density in the droplets $n$. are obtained By comparing the results from spectra taken at both low and high optical pumping powers, the EHD binding energies from different samples under different experimental conditions can be estimated. [9] One can find that with decreasing lateral size from $500 \mathrm{~nm}$ to $40 \mathrm{~nm}$, the EHD binding energy changes from $11.3 \mathrm{meV}$ to $13.6 \mathrm{meV}$, and the electron-hole pair density increases indicating an increase in the radius of the EHD in confined system.

The origin of band 9 in Fig. 1 needs more investigation, but a possible explanation for the intensity drop and disappearance of it with reducing wire width is that this band may come from strain in the epitaxial layers. As half of the MQWs was etched into wide wires, the strain will be partially relaxed, causing a decrease in its PL intensity. As the wires narrow further, more dry etching damaged areas are probed in the experiments. Although half of the MQWs remains untouched, the surface damage and the total relaxation of strain in the MQW wires may extinguish the PL signal (band 9) from the samples.

Through detailed study of the behavior of the new feature $X_{I},{ }^{[11]}$ we have identified it as an impurity related emission. With the increase of temperature, the PL intensity of $X_{I}$ gradually drops to zero compared to the intrinsic PL emission $\mathrm{XNP}_{\mathrm{Si}-\mathrm{Ge}}$. At a certain temperature, the PL intensity of $X_{I}$ saturates with the increase of the optical pumping power. These properties indicate that $X_{I}$ is a transition related to impurities. We propose that $X_{I}$ arises from impurity states of unknown origin located at or in Si layers close to the heterointerfaces. The feature in low temperature PL spectra may be from an unidentified impurity-to-band transition as it was also observable in photoreflectance measurements. [11]

In conclusion, we have investigated the photoluminescence of dry etched free standing $\mathrm{Si} / \mathrm{Si}_{1-\mathrm{x}} \mathrm{Ge}_{\mathbf{x}} \mathrm{MQW}$ wires. The results show that in addition to the luminescence due to a strain relaxation process arising from the etching, an enhanced emission from EHD in the wires with reduced lateral dimension and a new feature probably due to impurity states located at the Si/SiGe heterointerfaces are also observed.

The authors would like to thank the SERC (UK) and DTI for partial financial support and the technical staff of the Nanoelectronics Research Centre of the University of Glasgow for their assistance during the course of this work.

\section{References:}

[1] See, for example, J.H. Davies and A.R. Long, eds, Physics of Nanostructures (IOP, Bristol, 1992).

[2] D.J. Robbins, L.T. Canham, S.J. Barnett, A.D. Pitt and P. Calcott, J. Appl. Phys. 71 (1992) 14071413.

[3] L. Vescan, A. Hartmann, K. Schmidt, Ch. Dieker, H. Luth and W. Jager, Appl. Phys. Lett. 60 (1992) 2183-2185.

[4] G. Abstreiter, in Phys. of Semicond. ed. by P.Jiang and H.-Z.Zheng (World Scientific, Singapore, 1992).

[5] H. Presting, H. Kibbel, M. Jaros, R.M. Turton, U. Menczigar, G. Abstreiter and H.G. Grimmeiss, Semicon. Sci. Technol. 7 (1992) 1127-1136.

[6] Y.S. Tang, C.D.W. Wilkinson, C.M. Sotomayor Torres, D.W. Smith, T.E. Whall and E.H.C. Parker, Superlatt. Microstruct. 12 (1992) 535-538.

[7] Y.S. Tang, C.D.W. Wilkinson, C.M. Sotomayor Torres, D.W. Smith, T.E. Whall and E.H.C. Parker, Solid State Commun. 85 (1993) 199-202.

[8] Y.S. Tang, C.D.W. Wilkinson, D.W. Smith, T.E. Whall \& E.H.C. Parker, (unpublished)

[9] Y.S. Tang, C.D.W. Wilkinson, C.M. Sotomayor Torres, D.W. Smith, T.E. Whall \& E.H.C. Parker, (unpublished)

[10]H. Kalt, K. Reimann, W.W. Ruehle, M. Rinker \& E. Bauser, Phys. Rev. B42 (1990) 7058-7061.

[11]Y.S.Tang, C.D.W.Wilkinson, C.M.Sotomayor Torres, D.W.Smith, T.E.Whall and E.H.C.Parker, Appl. Phys. Lett. 63 (1993) xxx-xxx. (July 26 issue) 